\title{
Mulheres no Capitalismo: Notas para uma educação feminista
}

\author{
Women in Capitalism: Notes for a feminist education \\ Mujeres en el Capitalismo: Notas para una educación feminista
}

Recebido: 18/05/2021 | Revisado: 27/05/2021 | Aceito: 31/05/2021 | Publicado: 13/06/2021

\author{
Laryssa Louzada de Assis \\ ORCID: https://orcid.org/0000-0002-0644-9357 \\ Universidade Federal do Rio Grande, Brasil \\ E-mail: laryecra@gmail.com \\ Tamires Lopes Podewils \\ ORCID: https://orcid.org/0000-0002-9683-0214 \\ Universidade Federal do Rio Grande, Brasil \\ E-mail: podewils.t@gmail.com
}

\begin{abstract}
Resumo
Este artigo apresenta o feminismo como prática de uma educação libertadora. Resgata a História das mulheres, problematizando a morte de milhares de "bruxas", na Europa e no mundo, no começo da modernidade e analisa o papel designado à mulher pelo sistema capitalista. O estudo apresenta a história da submissão das mulheres ao sistema capitalista e levanta o seguinte problema: Que contribuições o estudo da ascensão do sistema capitalista apresenta para uma educação feminista? Como objetivo geral delineou-se a ideia de apresentar a história da submissão das mulheres ao sistema capitalista no sentido de compreender quais contribuições o estudo da ascensão capitalista apresenta para uma educação feminista. Foram elencados os seguintes objetivos específicos: i. Analisar, a partir da obra O Calibã e a Bruxa, a história da ascensão do capitalismo e a situação das mulheres; ii. engendrar, a partir de bibliografia diversa, uma perspectiva sobre a situação atual das mulheres no capitalismo contemporâneo; iii. apresentar os conteúdos atinentes a uma educação feminista e; iv. refletir sobre as potencialidades da educação feminista em todos os níveis de ensino. O resgate bibliográfico foi a trajetória metodológica dessa pesquisa e a forma de organizar o estudo foi a Leitura Imanente (LESSA, 2014). Aponta-se que apesar do reconhecimento da necessidade de uma transformação radical do sistema econômico, não é necessário que tenhamos uma transformação no modo de produção para que comecemos a desatar os nós das amarras às quais somos submetidas e a educação feminista é uma das maneiras de fazê-lo.
\end{abstract}

Palavras-chave: Educação libertadora; Feminismo; Capitalismo; Consciência de classe; Patriarcado.

\begin{abstract}
This article presents feminism as a practice of liberating education. It rescues the History of women, problematizing the death of thousands of "witches", in Europe and in the world, in the beginning of modernity and analyzes the role assigned to women by the capitalist system. The study presents the history of the submission of women to the capitalist system and raises the following problem: What contributions does the study of the rise of the capitalist system represent to a feminist education? As a general objective, the idea of presenting the history of the submission of women to the capitalist system was outlined in order to understand what contributions the study of capitalist ascension presents to a feminist education. The following specific objectives were listed: i. Analyze, based on the work "O Calibã e a Bruxa", the history of the rise of capitalism and the situation of women; ii. engender, from a diverse bibliography, a perspective on the current situation of women in contemporary capitalism; iii. to present the contents related to a feminist education and; iv. reflect on the potential of feminist education at all levels of education. The bibliographic rescue was the methodological trajectory of this research and the way to organize the study was the Immanent Reading (LESSA, 2014). It is pointed out that despite the recognition of the need for a radical transformation of the economic system, it is not necessary that we have a transformation in the mode of production in order for us to begin to untie the knots of the bonds to which we are subjected and feminist education is one of the ways of doing it.
\end{abstract}

Keywords: Liberating education; Feminism; Capitalism; Class counsciousness; Patriarchate.

\section{Resumen}

Este artículo presenta al feminismo como una práctica de educación liberadora. Rescata la Historia de la mujer, problematizando la muerte de miles de "brujas", en Europa y en el mundo, en los inicios de la modernidad y analiza el papel asignado a la mujer por el sistema capitalista. El estudio presenta la historia del sometimiento de las mujeres al sistema capitalista y pla ntea el siguiente problema: ¿Qué aportes el estudio del surgimiento del sistema capitalista hace a la educación feminista? Como objetivo general, se esbozó la idea de presentar la historia del sometimiento de las mujeres al sistema capitalista para comprender qué aportes presenta el estudio de la ascensión capitalista a la educación feminista. Se enumeraron los siguientes objetivos específicos: i. Analizar, a partir de la obra O Calibã ea Bruxa, la 
historia del auge del capitalismo y la situación de la mujer; ii. engendrar, desde una bibliografía diversa, una perspectiva sobre la situación actual de la mujer en el capitalismo contemporáneo; iii. presentar los contenidos relacionados con una educación feminista y; iv. reflexionar sobre el potencial de la educación feminista en todos los niveles educativos. El rescate bibliográfico fue la trayectoria metodológica de esta investigación y la forma de organizar el estudio fue la Lectura Inmanente (LESSA, 2014). Se señala que a pesar del reconocimiento de la necesidad de una transformación radical del sistema económico, no es necesario que tengamos una transformación en el modo de producción para que comencemos a desatar los nudos de los lazos a los que nos enfrentamos. son sometidos y la educación feminista es una de las formas de hacerlo.

Palabras clave: Educación liberadora; Feminismo; Capitalismo; Conciencia de clase; Patriarcado.

\section{Introdução}

A sociedade carece de uma educação libertadora que potencialize a capacidade de intervenção dos estudantes, para que possam transformá-la a partir da consciência de sua realidade. A Educação, sobretudo, tem o dever de contrapor a lógica de dominação sobre determinadas classes sociais, para isso, deve reconhecer a necessidade de outras pedagogias, capazes de enaltecer a coexistência de identidades, trajetórias e culturas em equidade. É primordial que o ato educativo fomente enfrentamentos de ideias e das concepções de mundo implícitas nelas, porque educar é um ato político de emancipação social e subversão às regras dominantes. Por isso, em tempos extremos para a educação no Brasil, essa pesquisa é um convite para refletila como prática de liberdade e transformação social.

O presente artigo apresenta o feminismo como prática de uma educação libertadora com foco em desenvolver crianças autogestionárias, com habilidades e iniciativa para problematizar a experiência social e transformá-la. Para isso, resgata a História das mulheres, do Feudalismo ao Capitalismo, problematizando a morte de milhares de "bruxas", na Europa e no mundo, no começo da modernidade e analisa o papel designado à mulher pelo sistema capitalista. Portanto, investiga como a degradação do poder das mulheres modificou suas vidas desde então através do controle patriarcal e da divisão sexual do trabalho através de uma perspectiva de consciência de classe. Nesse sentido, como objetivo geral delineou-se a ideia de apresentar a história da submissão das mulheres ao sistema capitalista no sentido de compreender quais contribuições o estudo da ascensão capitalista apresenta para uma educação feminista.

Ademais, problematiza as instituições de ensino como mantenedoras de um sistema misógino que legitima as diferenças e contribui para os preconceitos de gênero, tendo como uma de suas finalidades desenvolver uma prática pedagógica que vise a igualdade de gênero e o combate ao sexismo. Sendo assim, levantamos o seguinte problema de pesquisa: Que contribuições o estudo da ascensão do sistema capitalista apresenta para uma educação feminista?

Com o intuito de responder nosso problema de pesquisa, elencamos os seguintes objetivos: i. Analisar, a partir da obra O Calibã e a Bruxa, a história da ascensão do capitalismo e a situação das mulheres; ii. engendrar, a partir de bibliografia diversa, uma perspectiva sobre a situação atual das mulheres sob o capitalismo contemporâneo; iii. apresentar os conteúdos atinentes a uma educação feminista para a atualidade e; iv. refletir sobre as potencialidades da educação feminista em todos os níveis de ensino.

Para isso, organiza-se em cinco tópicos textuais, inicialmente, apresenta o viés metodológico adotado na pesquisa, em “1. Percurso Metodológico". Posteriormente analisa dados históricos em “2. A degradação do poder das mulheres e o Capitalismo", reflete acerca da consequência desses acontecimentos na vida contemporânea das mulheres em "3. Neuroses, suicídios, dessexualização: doenças ocupacionais da dona de casa" e considera como o feminismo pensa a sociedade em "4. Consciência de classe, patriarcado e resistência: conteúdos para uma educação feminista." Por fim, reivindica o feminismo como prática pedagógica em "5. Como educar crianças feministas". 


\section{Metodologia}

O presente artigo foi elaborado a partir de uma pesquisa de natureza teórica. O resgate bibliográfico foi a trajetória na elaboração efetiva dessa pesquisa, com finalidade de complementar as investigações realizadas anteriormente e contribuir com os estudos do tema selecionado e na busca por soluções para o problema elaborado no projeto de pesquisa.

A forma técnica de se organizar esse estudo foi a Leitura Imanente (Lessa, 2014). Tal técnica caracteriza-se por um conjunto de procedimentos que consiste em buscar uma compreensão profunda do texto, através da leitura e análise inicial de suas partes (parágrafos, capítulos, etc.) que devem ser examinadas, a princípio, como uma totalidade independente do texto, a fim de determinar seu raciocínio retirando e anotando de cada parte a ideia fundamental para que seja possível uma aproximação às razões do autor para escrever aquele fragmento.

O desdobramento desse processo, formam anotações e, posteriormente, um único texto, expondo a construção de ideias dos textos em análise. Mesmo quando o sentido do excerto não for compreendido, deve-se transformar a anotação em questionamento, conforme explica Lessa (2014, p.69): “[...] o texto afirma x e, em seguida, y. Depois de y, afirma z. O que ele quer dizer com y nesse contexto?’. Esse procedimento possibilita que conforme a leitura gradativa ou a evolução da compreensão do leitor, essa dúvida seja solucionada.

Nesse momento da investigação em que estamos nos aproximando dos parágrafos e das suas relações, é mais frequente do que raro que as pessoas entrem em um quê - permitam-me a brincadeira - de “depressão". [...] Todos passamos por isso. Desenvolver a capacidade de colocar sob controle nossa subjetividade de tal modo a que não sejamos paralisados por essas (permitam-me, novamente) “depressões” faz parte do aprendizado de como estudar. Logo, contudo, essa sensação tenderá a ser substituída pela alegria (por vezes também desequilibrada, que beira a euforia) de estarmos aprendendo e conseguindo desvendar no mundo o que antes era um "mistério". Também no caso da euforia, algum controle da subjetividade deve se desenvolver, ainda que por razões opostas. (Lessa, 2014, p.71).

Contudo, nenhuma das estratégias citadas acima teriam eficiência sem um estudo sistemático e o rearranjo da vida cotidiana, pois é um trabalho que demanda tempo, esforço e envolvimento pessoal, porque conforme Lessa (2014, p. 74): “Sem que tenhamos algum prazer no estudo, o esforço que requer a leitura imanente se torna quase insuportável.” É imprescindível ressaltar que nesse tipo de leitura, em nenhum momento, busca-se compreender a nossa opinião ou a forma como nos sentimos acerca do conteúdo, pois, o que mais importa é o predomínio do texto sobre a nossa subjetividade. Mesmo assim, é preciso preparar nosso espírito e desvencilhar-nos dos desassossegos da vida cotidiana: redes sociais, distrações, responsabilidades. Isto porque, se tivermos a determinação e o privilégio de organizar uma rotina de estudos da forma que esse estudo foi pensado:

Em poucos minutos estaremos visitando as ideias mais geniais do mais genial pensador de algum momento da humanidade, estaremos elevando nosso intelecto ao máximo que a humanidade conseguiu fazer em um dado momento histórico. Estaremos reproduzindo, em nossas consciências, uma parte fundamental da trajetória da humanidade: não devemos permitir que nada da vida cotidiana, plena de alienações, atrapalhe essa incrível "viagem”. (Lessa, 2014, p.73).

Outra estratégia da Leitura Imanente que facilitou a construção dessa escrita foi desenvolver um mecanismo que possibilite a recuperação rápida e eficiente do que já foi estudado. Para isso, foi necessário converter as anotações dos segmentos em um esquema para que fosse possível retomar o texto com um olhar. Além disso, contei com a oportunidade de compartilhar leituras, ideias e concepções com o Grupo de Leituras Emergentes ${ }^{1}$ acerca de duas das principais obras estudadas para essa pesquisa, o que por certo não substitui o estudo individual, mas complementou-o reunindo compreensões de outras pessoas e enriquecendo meus estudos. Lessa (2014) ainda ressalta que estudar a teoria revolucionária é uma enorme aventura porque:

${ }^{1}$ O Grupo de Leituras Emergentes (GLE) é fruto do Grupo de Estudos em Filosofias Emergentes (FURG). 
[...] Tal como um salto de paraquedas, é uma opção total, radical e completa. Nem um átomo da pessoa fica imune, todo o seu ser é envolvido: dos afetos à razão, do seu corpo biológico às emoções mais sublimes. A segunda delas é que dissolve o misterioso do mundo em um conhecimento que comporta coisas que não conhecemos, porém não mais comporta "mistérios". [...] Diferentemente da idiotizante divisão de trabalho da ciência burguesa, não há nada que não seja importante ao revolucionário conhecer, assim como não há nada no universo que não lhe diga respeito. (Lessa, 2014. p.77).

Além disso, o autor afirma que o ato de estudar é profundamente desafiador do mundo burguês, pois: “[...] nos torna mais curiosos, nos torna mais inquietos, nos torna mais sensíveis, nos torna mais questionadores: nos faz mais humanos. (Lessa, 2014, p.78)". Em decorrência do desenvolvimento dessas compreensões, há a possibilidade de conferir uma direção ao nosso destino e tomar controle de partes significativas de nossas vidas cotidianas. Portanto, ratifico o que diz Lessa (2014, p.78) “[...] não há meio-termo possível: a autenticidade se expressa nessa exigência pela radicalidade da opção feita”, ou seja: “Ao estudo, camaradas! Que belas tempestades os aguardem nas próximas esquinas!” (Lessa, 2014, p.78).

\section{Resultados}

\subsection{A Degradação do poder das mulheres e o nascimento do Capitalismo}

Neste tópico apresentaremos uma análise, a partir da obra O Calibã e a Bruxa-mulheres, corpo e acumulação primitiva, a história da ascensão do capitalismo e a situação das mulheres, correspondendo ao primeiro objetivo do presente artigo. A obra em estudo, publicada originalmente em inglês, no ano de 2004, foi traduzida para o português pelo coletivo feminista Sycorax e publicada no Brasil, apenas no ano de 2017.

Para analisar a História da mulher na sociedade, é fundamental observar que, conforme Federici (2017), o sistema capitalista não foi um produto do desenvolvimento evolutivo, mas sim uma contestação às lutas sociais que atemorizavam seu poder - tendo como pretensão estabelecer a servidão como relação de classe através da expropriação por meio da violência. Nessa perspectiva, questiona-se: qual o papel da mulher no sistema capitalista e quais as consequências do surgimento deste modelo econômico para o modo de viver das mulheres?

A imposição da submissão das mulheres, assim como o racismo, é parte da estrutura do capitalismo desde sua origem e é essencial à sua consolidação. Mulheres reunidas em coletivos reconhecem seus direitos, portanto, são perigosas para o novo sistema econômico, que não teve um período de transição natural desde o feudalismo, pois não foi uma sequência evolutiva da economia mundial, mas sim um sistema imposto a duras penas para a grande maioria das populações. Nesse abrupto rompimento, a segregação feminina aos lares e a obediência aos homens foi a alternativa de sobrevivência daquelas mulheres que temiam queimar nas fogueiras como bruxas. (Federici, 2017).

É conhecimento global o fato de que as bases do sistema capitalista só foram construídas devido ao enorme número de pessoas da classe trabalhadora, que após o cercamento de suas terras e bens, não tiveram outra opção, senão, vender sua força de trabalho. Nesse momento houve um processo de assujeitamento das trabalhadoras e trabalhadores às longas jornadas de trabalho por não terem mais acesso às suas formas de subsistência. Ou seja, para o capitalismo, convinha então, anular o poder que as mulheres tinham sobre seus corpos e sobre sua sexualidade, para que pudessem tornar-se, segundo Federici (2017), o sustentáculo desse sistema econômico, sujeitando seus corpos à reprodução da força de trabalho.

A degradação do poder das mulheres começou a ser instituída durante o Feudalismo, quando o uso da terra e dos espaços comunais $^{2}$ fomentava a coesão e a cooperação comunitária. Por possuírem menos direito à terra, a população feminina era mais

\footnotetext{
2 Área do feudo de uso coletivo. Eram os bosques, florestas e pastos. Porém, dependendo do feudo existiam regras para sua utilização. Em muitos locais da Europa, era comum a proibição da caça realizada por servos em terras comunais. Os servos podiam levar seus animais para pastarem nestas terras, assim como pegar lenha. (Federici, 2017).
} 
dependente das terras comunais do que os homens, pois delas tiravam sua subsistência, portanto, esses espaços coletivos eram o centro da vida social das mulheres, autônomo da perspectiva masculina, onde o comunismo primitivo do vilarejo feudal se dava. (Federici, 2017).

No campesinato, as terras eram transmitidas aos homens, mas há registros de mulheres que herdaram e administraram propriedades em seu nome, além disso, as atividades de reprodução social - não eram desvalorizadas. As tarefas das servas, em cooperação com outras mulheres, valorizavam as relações coletivas que predominavam frente às relações familiares. Nesse sentido, a divisão sexual do trabalho poderia ser considerada como uma fonte de poder e proteção para as mulheres. Essas relações de proximidade acabavam por fortalecer coletivos que culminavam em enfrentamentos importantes, já que grande parte dos motins incluíam mulheres e alguns protestos eram exclusivamente femininos. (Federici, 2017).

A ascensão do capitalismo fomentou guerras, violência e até mesmo reformas religiosas, ao mesmo tempo que que promovia o cercamento e banimento das terras comunais, A partir de Federici (2017) é possível compreender que o objetivo de tal projeto foi decompor a coesão social, deixando famílias, idosos, jovens sem poder de subsistência dependendo agora do trabalho assalariado, que surge como instrumento de controle do Capital sobre as pessoas.

A caça às bruxas foi, também, um instrumento de controle. O domínio dos corpos e da sexualidade feminina é reforçado, trazendo a humilhação e tortura, culminando e na morte cruel como alternativa às mulheres que não se adaptassem ao desempenho do papel atribuído a elas pelo sistema nascente. O capitalismo surgia e já determinava que a sexualidade deveria estar a serviço da economia, fazendo nascer novos trabalhadores - além de manter os trabalhadores satisfeitos através do uso de seus corpos.

As mulheres que tinham seus corpos subsumidos a economia eram não apenas as esposas, donas de casa, mas também aquelas que foram submetidas à prostituição. Algumas recusaram a dominação imposta pela vida doméstica, outras lá estavam devido à destituição de suas terras, vivendo em extrema pobreza. Nesse ínterim, a violência era estatizada e nas palavras de Silvia Federici:

[...] à medida que a caça às bruxas avançava, aprovavam-se leis que castigavam as adúlteras com a morte [...] e a prostituição era colocada na ilegalidade, assim como os nascimentos fora do casamento, ao passo que o infanticídio foi transformado em crime capital. Ao mesmo tempo, as amizades femininas tornaram-se objeto de suspeita, denunciadas no púlpito como uma subversão da aliança entre marido e mulher, da mesma maneira que as relações entre mulheres foram demonizadas pelos acusadores das bruxas, que as forçavam a delatar umas às outras como cúmplices do crime. Foi também neste período que, como vimos, a palavra gossip [fofoca], que na Idade Média significava "amiga", mudou de significado, adquirindo uma conotação depreciativa: mais um sinal do grau a que foram solapados o poder das mulheres e os laços comunais. (Federici, 2017, pp.334-335)

As mulheres passam a ser vistas como desobedientes, insubordinadas, levianas, instrumentos do pecado e da luxúria, histéricas, fofoqueiras e incapazes. Dessa forma, para esta sociedade, surge então a figura daquelas que não agiam cegamente sob o poder de um homem: a esposa desobediente, a desbocada, a bruxa e a puta, mulheres que, de acordo com Federici (2017) eram o alvo favorito de dramaturgos, escritores populares e moralistas.

Todo esse processo se manifesta como uma construção ideológica que, por um lado, é reflexo da ordem social vigente e, por outro, sustenta a construção e manutenção da exploração material das mulheres. Esse movimento constrói ideários sociais que acabam contribuindo com os estereótipos de classe, gênero e raça, ou seja, compactuando com os interesses ideológicos de quem detém os meios de produção - ideias que determinam a "moral" e os "bons costumes" da sociedade capitalista. Essa organização do ideário coletivo sustenta e fortalece um conjunto de concepções e atitudes depreciativas que compõem as relações sociais e prejudicam agrupamentos determinados pela sociedade como inferiores, reforçando as relações de poder impostas pela hegemonia dominante. 
Portanto, como condição para o crescimento desse modelo econômico está o controle dos corpos femininos e de sua sexualidade. Para assegurar a reprodução da mão de obra, a mulher é agora segregada ao lar, responsável por sua gestão, trabalhando servilmente, gerando e educando novos trabalhadores, desvalorizada e sujeita às vontades dos maridos, como se fossem civilmente incapazes. As mulheres tiveram sua sexualidade demonizada na figura das bruxas queimadas nas fogueiras, portanto, mediante essa possibilidade, basta apenas sucumbir às pressões sociais e adaptar-se às imposições da nova ordem patriarcal, para que assim, surja a família como instituição, conforme Federici (2017), para a apropriação e para o ocultamento do trabalho das mulheres. Dessa forma:

[...] na nova organização do trabalho, todas as mulheres (exceto as que haviam sido privatizadas pelos homens burgueses) tornaram-se bens comuns, pois uma vez que as atividades das mulheres foram definidas como não trabalho, o trabalho das mulheres começou a se parecer com um recurso natural, disponível para todos, assim como o ar que respiramos e a água que bebemos. (Federici, 2017, p.191)

Para o capitalismo, essas mulheres precisam estar longe umas das outras, para que não percebam o que têm em comum, para que não utilizem seu poder de participação política ativa, para que não tenham controle de seus corpos e ocupem o trabalho de reprodução da vida, sem remuneração ou reconhecimento, para o trabalho em massa e para a riqueza de poucos.

O sistema capitalista tem então, neste ponto da história, um cenário fértil para sua implementação e manutenção com corpos masculinos disponíveis para serem dominados em prol do "desenvolvimento econômico" e corpos femininos subjugados disponíveis para uso abusivo e recreativo dos homens e para a reprodução da mão de obra - afinal, quanto tempo pode durar uma vida de exploração? Novos corpos precisam nascer para serem explorados quando o proletariado atual estiver cansado demais para ser produtivo, e nós, mulheres, somos as "máquinas" que reproduzem a força de trabalho por, segundo eles, "vocação natural".

\subsection{Neuroses, suicídios, dessexualização: doenças ocupacionais da dona de casa ${ }^{3}$}

Neste tópico, expomos uma perspectiva sobre a situação atual das mulheres sob o capitalismo contemporâneo tecida a partir da análise de uma bibliografia diversa. Para tanto, ressaltamos a desvalorização do trabalho feminino e apresentaremos os índices nacionais de segurança pública, reafirmando que a caça às bruxas nunca terminou e que as mulheres nunca deixaram de resistir. (Federici, 2017).

Em Calibã e a Bruxa, Silvia Federici (2017) nos mostra como a prostituição e o estupro são legalizados como forma de proporcionar poder aos homens trabalhadores. Assim como foi sustentáculo para o surgimento do capitalismo, hoje a cultura do estupro continua latente e as mulheres ainda precisam enfrentar uma sociedade que as vê como um recurso natural, disponível para todos. Justifica-se que seus corpos sejam violados conforme as roupas que vestem, o comportamento que adotam ou, os lugares que frequentam.

Santos et al. (2020), ao discutir a presença da cultura do estupro nas letras musicais afirma que elas são carregadas de "marcas culturais de um país que até hoje vive os valores do patriarcado [...] e estabelece a prática de estupro como algo natural, já que pode ser exibida ao público e é aceita pela sociedade.” (p.11)

Conforme o Anuário Brasileiro de Segurança Pública (FBSP, 2020), os resultados encontrados até 2019 mostram que, até então, uma agressão física contra mulheres ocorre a cada dois minutos no Brasil. Ademais, uma mulher é estuprada a cada oito minutos e há 266.310 registros de lesão corporal dolosa em decorrência de violência doméstica e 66.123 vítimas de estupro - e de estupro de vulnerável - sendo 85,7\% das vítimas do sexo feminino e 57,9\% com idade igual ou inferior a 13 anos.

\footnotetext{
${ }^{3}$ Título elaborado em referência à obra de Silvia Federeci “O ponto zero da revolução: Trabalho doméstico, reprodução e luta.” publicada no Brasil em 2019.
} 
O poder engendrado pelo Estado e o capitalismo sobre os corpos femininos, que se manifestou na caça às bruxas durante a idade média, não cessou. Se olharmos, de maneira mais específica, os índices referentes ao feminicídio percebe-se que $89.9 \%$ das vítimas foram mortas por seus companheiros, sendo que 66,6\% delas eram negras. Além disso, os casos de violência contra LGBTQIA + tiveram um aumento de 7,7 \% nos casos de agressão (FBSP, 2020). Esses dados nos mostram que a violência no Brasil está diretamente relacionada com gênero, raça e classe. Além das acumulações de grandes fortunas em poucas mãos, o capitalismo, traz consigo também, a acumulação dos corpos femininos, violentados e/ou mortos em benefício de um modelo econômico.

Já em tempos de pandemia, pergunta-se, o que ocorreu com os índices de violência e quais desdobramentos foram provocados pelo isolamento social. De acordo com o Anuário Brasileiro de Segurança Pública, durante a pandemia Covid-19, obtivemos uma queda de 9,9\% nos registros de agressões em decorrência de violência doméstica nas delegacias durante o

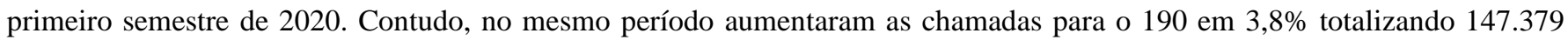
chamadas, resultando num aumento de 1,9\% em relação ao ano anterior com 648 vítimas de feminicídio. Ou seja, embora os índices de denúncias em delegacias maquiem a realidade contemporânea, fica explícito, que o isolamento social provocado pela pandemia, está aumentando os riscos de vida e submetendo à violência mulheres que, na maioria dos casos, moram com seus agressores.

Sousa et al. (2021) destaca que durante o período de isolamento social, as mulheres, que são vítimas de violência doméstica, ficaram "presas em suas casas" juntamente com seus agressores, portanto, com maiores dificuldades para denúncias, pedidos de ajuda, etc. Sendo assim, dentre as opressões do sistema capitalista, percebemos que, o ambiente doméstico, lugar destinado pelo capitalismo ao sexo feminino, torna-se também o cenário mais comum de feminicídio no Brasil.

Federici (2017) ressalta que a desvalorização do trabalho feminino e a discriminação sofrida pelas mulheres como mão de obra remunerada está diretamente relacionada à sua incumbência como trabalhadoras não assalariadas. No lar, as mulheres não só geram, alimentam e cuidam os filhos, mas também os educam. Nesse sentido, vemos grande parte dos elementos atinentes à Reprodução Social sendo realizados por elas.

No movimento de compreender que a Reprodução Social é desempenhada em sua maioria, por mulheres, a luta por salários pelo trabalho doméstico significa exigir o reconhecimento de que esse trabalho já é fonte de dinheiro para o capitalismo, pois, como ressalta Federici (2019a), o capital ganhou e ganha dinheiro quando cozinhamos, sorrimos e transamos. Isso porque o trabalho reprodutivo não se resume à manutenção de um lar ou ao preparo de alimentos, mas também à disposição sexual e emocional das mulheres, que estão a serviço dos egos feridos dos trabalhadores cansados.

Eles dizem que é amor. Nós dizemos que é trabalho não remunerado. Eles chamam de frigidez. Nós chamamos de absenteísmo. Todo aborto é um acidente de trabalho. Tanto a homossexualidade quanto a heterossexualidade são condições de trabalho..., mas a homossexualidade é o controle da produção pelos trabalhadores, não o fim do trabalho. Mais sorrisos? Mais dinheiro. Nada será tão poderoso em destruir as virtudes de cura de um sorriso. Neuroses, suicídios, dessexualização: doenças ocupacionais da dona de casa. (Federici, 2019b, p.40).

Isto posto, não é possível aceitar as relações sociais as quais o capitalismo reservou às mulheres. É essencial explicitar que não estamos fisicamente, sexualmente e emocionalmente disponíveis para agregar mais riquezas a um sistema que nos explora. Em conformidade com Federici (2019b, p.49) afirmamos que "Nós queremos chamar de trabalho o que é trabalho, para que, eventualmente, possamos redescobrir o que é amar e criar a nossa sexualidade, a qual nós nunca conhecemos". O salário para o trabalho doméstico, neste cenário, se apresenta como denúncia do trabalho oculto das mulheres, que consome suas vidas através da reprodução da força de trabalho.

Outro fator imposto aos modos de vida das mulheres, sob o capitalismo contemporâneo, em benefício da satisfação do outro e do consumismo é a comercialização de um padrão de beleza utópico difundido pela mídia e disseminado por construções 
ideológicas. Tal padrão, de acordo com Wolf (1992), é visto como uma reação violenta contrária aos avanços do feminismo, que utiliza as imagens de beleza feminina contra a evolução da mulher através da arma política que ela denomina como: o mito da beleza. Ele atém-se na busca pela aprovação masculina, fazendo com que poucas sejam as mulheres que se sentem confortáveis com a sua imagem e são capazes de amar o próprio corpo, independentemente de suas características, acrescentando casos de distorção de imagem, anorexia, vigorexia, entre outros, aos desafios da saúde da mulher. Para Federici:

É por isso que, magras ou gordas, de nariz grande ou pequeno, altas ou baixas, nós todas odiamos o próprio corpo. Nós o odiamos porque estamos acostumadas a vê-lo através de um olhar externo, com os olhos dos homens com quem nos encontramos, e com o mercado do corpo em mente. (Federici, 2019b, pp.59-60).

Ainda hoje, ser mulher significa enfrentar muitos desafios para garantir que seu lugar de fala seja respeitado. Ao adentrar a vida profissional, as mulheres se veem competindo no mercado de trabalho com homens que precisaram esforçar-se muito menos para chegar em uma posição hierárquica semelhante; e ainda assim, lidar com a desigualdade na divisão de tarefas em casa, temer a violência sexual, a desvalorização profissional e a possibilidade da violência doméstica. Silva et al. (2020) destaca que "[...] na raiz do contexto de violência doméstica, há um contexto social e cultural que legitima a desigualdade entre os gêneros, propiciando a prática da violência." (p.12)

Somado a isso, se vive, muitas vezes, nos ambientes de trabalho ou fora deles, o assédio moral e sexual. Em uma sociedade em que o feminicídio só aumenta, a discriminação social exclui e aliena e a pressão estética mata, muitas vezes, por complicações em procedimentos médicos/estéticos invasivos em busca da "beleza", é urgente reconhecer as raízes de tais problemas, para que assim, possamos transformá-los.

\subsection{Consciência de classe, patriarcado e resistência: conteúdos para uma Educação Feminista}

Neste tópico serão apresentados conteúdos atinentes a uma educação feminista para a atualidade fundados no reconhecimento da diversidade dos sujeitos e na consciência de classe. Assim, suscita o entendimento do patriarcado como uma organização sociopolítica de dominação. Além disso, problematiza as construções ideológicas difundidas pelos padrões de beleza midiáticos.

Gohn (2011) afirma que a sociedade "é ainda marcada pelas heranças coloniais da subserviência" (p. 356). Contrapõese que o feminismo pensa a sociedade como plural e defende a condição de igualdade entre homens e mulheres. Na sociedade atual, a educação tem a potência para criar essa realidade, por meio de uma educação feminista. Em nossa perspectiva, uma educação feminista questiona o patriarcado, o lugar em que a sociedade capitalista colocou a mulher, as funções que lhes atribuiu e os direitos que lhes foram negados. Para tanto, o feminismo deve reconhecer a classe trabalhadora como plural e deve considerar sua multiplicidade e diversidade.

Nessa esteira, é necessário observar a desigualdade social e a divisão do trabalho do ponto de vista das classes sociais. Pois, é notável o fato de que a maioria das vítimas da violência no Brasil possuem raça, gênero e classe específicos, que lidam com diferentes desdobramentos políticos e sociais diante de diferentes pautas reivindicatórias, e o mundo do trabalho não pode refletir diferente realidade do que a imposta socialmente. No mesmo sentido, é possível afirmar que:

Tampouco a classe trabalhadora global é composta exclusivamente de pessoas que trabalham por salários nas fábricas e nas minas. Igualmente fundamentais são aquelas que trabalham no campo e nas residências particulares; em escritórios, hotéis e restaurantes; em hospitais, creches e escolas; no setor público e na sociedade civil; o precariado, as pessoas desempregadas e aquelas que não recebem remuneração em troca de seu trabalho. [...] a maior parte da classe trabalhadora global é constituída de imigrantes, pessoas racializadas, mulheres - tanto cis como trans - e pessoas com diferentes capacidades, cujas necessidades e os desejos são renegados ou deturpados pelo capitalismo. (Aruzza et al., 2019, p.26). 
As dificuldades e privilégios de homens e mulheres no trabalho são diferentes, assim como, muitas vezes, são os seus salários. Mirla Cisne (2015) afirma que esse fator faz com que a dominação da classe operária seja legitimada quando a sociedade vê essa discriminação como uma especificidade da mulher. Ela é, na verdade, elemento fundamental para a exploração da classe trabalhadora e predomínio dos privilégios das classes dominantes, assim como o racismo e a LGBTQIA+fobia. Cisne (2015, p.26) afirma que "Há, portanto, uma nítida hierarquia que revela desigualdades no interior de uma mesma classe. Tal hierarquia da estrutura da desigualdade social segue a seguinte ordem: homens brancos, mulheres brancas, homens negros (e pardos) e mulheres negras".

Sendo assim, o reconhecimento das diferenças dos sujeitos inseridos em uma mesma classe social tem por objetivo, não o isolamento de cada fractal deste coletivo, mas sim, perceber os sujeitos em sua totalidade, através das suas particularidades, levando em conta que muitos desses são atravessados por mais de um tipo de segregação, e, por isso, possuem diferentes lutas. Essas lutas são os esforços que compõem o coletivo da classe trabalhadora, pois, para Cisne (2015), é nas relações de produção, que a dominação, a exploração e a opressão se entrecruzam. Mirla Cisne, ainda afirma que:

Desse modo, considerar a diversidade da classe faz-se necessário, contudo, sem se perder na ênfase das diferenças em detrimento da luta política engendrada pela criação dos sujeitos coletivos em torno de uma luta classista, que deve ser o ponto comum entre todas as lutas que buscam o fim das desigualdades sociais. (Cisne, 2015, p.31).

A classe trabalhadora é a parte principal do processo capitalista, pois, é a única mercadoria capaz de gerar valor, entretanto, segue sendo também a classe social que não acessa a riqueza material que produz. Os trabalhadores são os produtores dos recursos e da força social capaz de mudar o mundo. Porém, dependem da organização social e da mediação coletiva, pois seus conflitos não são individuais, ou seja, devem ser vividos por meio de um grupo, unido por vínculos políticos que embora englobe diferenças, reconhece-se nas reivindicações em comum.

No capitalismo, o patriarcado pode ser compreendido como uma organização sociopolítica que dita que o poder está nas mãos dos homens em superioridade às mulheres constituindo uma base de privilégios para a dominação masculina, que muitas vezes, é representado pela igreja através da instituição do casamento católico sendo considerado sagrado. De acordo com Saffioti (2004), é um regime da dominação-exploração das mulheres pelos homens e está presente na sociedade assim como em todos os aspectos de nossas vidas, pois:

Do mesmo modo como as relações patriarcais, suas hierarquias, sua estrutura de poder contaminam toda a sociedade, $\mathrm{o}$ direito patriarcal perpassa não apenas a sociedade civil, mas impregna também o Estado. Ainda que não se possa negar o predomínio de atividades privadas ou íntimas na esfera da família e a prevalência de atividades públicas no espaço do trabalho, do Estado, do lazer coletivo, e, portanto, as diferenças entre o público e o privado, estão estes espaços profundamente ligados e parcialmente mesclados. (Saffioti, 2004, p.54).

Considerando a segregação e alienação que o patriarcado e o capitalismo nos impõem, tivemos nossas raízes e nossos laços tomados de nós. Por isso, afirmamos que as lutas contra o sexismo, o racismo e a LGBTQIA+fobia não são lutas segregadas, mas sim lutas que dependem da consciência de classe. Consciência essa que não se atém apenas à mera percepção psicológica quanto à própria situação de exploração, pois as conquistas dessas lutas serão sempre limitadas, por que ainda visam mudanças dentro do sistema capitalista de reprodução perpetuando a manutenção dessas relações e não questionando-as. É necessário que os objetivos e as ações das lutas sociais sejam baseadas na compreensão das contradições das relações de poder, baseada na consciência de classe, buscando a superação das relações capitalistas, combatendo assim um sistema fetichista e violento.

Para tanto, como forma de resistência, destacamos aqui a coletividade que nos foi tomada com os cercamentos das terras comunais e a expropriação de nossas terras durante o feudalismo, quando o capitalismo ainda era apenas uma grande ameaça. A coletividade é imperativa para que as lutas, reivindicatórias e movimentos sociais tenham força. Salientamos três movimentos nacionais, que Cisne (2015) denomina como os mais representativos das lutas das mulheres brasileiras na atualidade: O 
Movimento de Mulheres Camponesas (MMC), a Marcha Mundial das Mulheres (MMM) e a Articulação de Mulheres Brasileiras (AMB).

Conforme Mirla Cisne (2015), a AMB percebe-se como um movimento feminista anticapitalista que busca, além das respostas às necessidades das mulheres, também a confrontação ao Estado burguês racista e patriarcal através de mobilizações dirigidas à militância feminina, declinando qualquer forma de hierarquia entre mulheres, direcionada à transformação social e à pluralidade. A Marcha Mundial das Mulheres (MMM) define-se como um movimento definido pela centralidade na mobilização e organização de suas campanhas atuando em prol da autonomia econômica das mulheres e a luta contra a apropriação dos corpos femininos, tendo como eixo estruturante a luta anticapitalista.

A MMM ressalta a dimensão classista, geracional e racial como preocupações feministas e objetiva a igualdade e a construção de uma sociedade justa e não predatória ao meio ambiente. O Movimento das Mulheres Camponesas (MMC) é composto por mulheres camponesas engajadas nas lutas classistas de militância e motivadas pelas lutas da oposição sindical rural. O MMC ressalta as diferenças de direitos entre as mulheres da cidade e as mulheres do meio rural que, muitas vezes, não possuem direitos mínimos, como carteira de trabalho assinada pelo empregador e busca o direito de viver com dignidade e igualdade para todos. (Cisne, 2015).

Os exemplos da luta feminista brasileira aqui apresentados, possibilitam colocarmos a educação feminista como um horizonte muito próximo. Já conseguimos reconhecer alguns conteúdos que seriam pertinentes ao processo educativo, desde uma perspectiva feminista e anticapitalista. Nas palavras de Cinzia, Tithi e Nancy:

[...] o feminismo que vislumbramos tem como objetivo atacar as raízes capitalistas da barbárie metastática. Recusandose a sacrificar o bem-estar da maioria a fim de proteger a liberdade da minoria, ele luta pelas necessidades e pelos direitos da maioria - das mulheres pobres e da classe trabalhadora, das mulheres racializadas e das migrantes, das mulheres queer, das trans e das mulheres com deficiência, das mulheres encorajadas a enxergar a si mesmas como integrantes da "classe média" enquanto o capital as explora. E isso não é tudo. Esse feminismo não se limita às "questões das mulheres" como tem sido tradicionalmente definido. Defendendo todas as pessoas que são exploradas, dominadas e oprimidas, ele tem como objetivo se tornar uma fonte de esperança para a humanidade. (Aruzza et al., 2019, p.21).

Com a esperança em foco, ainda é necessário um processo reflexivo constante sobre as possibilidades ideais e materiais de uma educação feminista.

\subsection{Como educar crianças feministas? ${ }^{4}$}

Neste tópico, buscaremos refletir sobre as potencialidades da educação feminista em todos os níveis de ensino. Para isso, problematizamos a Educação como transmissora da ideologia dominante e fomentamos o feminismo como prática pedagógica.

Estudar a história das mulheres e de suas lutas por direitos na sociedade traz uma grande preocupação: Como educar crianças feministas? Como educar para a igualdade social, política e econômica? É notável que para criar um futuro contra a violência de gênero e pela igualdade de direitos precisamos repensar a Educação desde seu início, na Educação Infantil. Se ainda vivemos em uma sociedade misógina, podemos inferir que a Educação teve grande contribuição na constituição do sistema de crenças e preconceitos instituídos pelo patriarcado.

As mulheres precisam conhecer a sua história e compreender como as relações de poder se deram ao longo dos tempos, portanto, as mulheres e os homens precisam estudar feminismo. O feminismo precisa ser estudado não somente no Ensino Superior, mas também no Ensino Médio, Fundamental e apresentado na Educação Infantil. Os cursos de licenciatura deveriam

\footnotetext{
${ }^{4}$ Título elaborado em referência à obra de Chimamanda Ngozi Adichie "Para educar crianças feministas: um manifesto", publicada no Brasil em 2017.
} 
ter esse elemento em suas grades curriculares, não apenas em uma disciplina, mas em todas elas, não somente no conteúdo, mas, na prática pedagógica, na maneira de se relacionar com os alunos, na escolha dos autores (as) a serem estudados (as).

Qual seria a porcentagem de conteúdos científicos estudados nas universidades que foram produzidos por mulheres? As autoras feministas são estudadas nas universidades? Essas autoras pertencem a que classe e raça? Falam da realidade de qual país ou continente? Para quem elas falam e quem elas representam? O autor(a) que você usa abrange a realidade de todos os seus alunos? Ou alguém ali é deixado de fora?

A resposta a esses questionamentos pode auxiliar um(a) educador(a) a repensar a sua prática indicando como ela pode se tornar mais integradora e rica. Há de afirmar-se que, embora muito idealizado, o mundo universitário não é uma garantia de escolha mais libertadora que o mercado de trabalho privado. Não basta estar inserido em um ambiente academicista, pois:

Uma posição no mundo acadêmico tampouco é um caminho para se tornar mais realizada ou criativa. Na ausência de um movimento forte de mulheres, o trabalho na academia pode ser sufocante, porque você deve atingir padrões que você não tem o poder de determinar e, logo, você começa a falar um idioma que não é o seu. (Federici, 2019, p.124).

No contexto da licenciatura em Pedagogia, questionamos: Como é possível ensinar História da Educação sem falar da História das mulheres? Como é possível falar da função social da escola desconsiderando que as escolas foram também responsáveis por ensinar e reforçar o preconceito e a misoginia? Como pensar que sociedade queremos formar ao planejarmos o trabalho docente sem pensar em um futuro de igualdade de direitos para homens e mulheres? Como podemos pensar a Educação das crianças sem entender como surgiu a sociedade que divide meninos e meninas em filas, brincadeiras e brinquedos diferentes ou que ensine que ser menina é usar rosa e menino azul?

Machado (2012) informa que: “[...] como não existe uma intenção pedagógica formulada para o tratamento das diferenças sexuais, os dispositivos pedagógicos reproduzem arranjos tradicionais de gênero, [...] por não haver um planejamento didático que intencione ruptura com os esquemas de pensamento[...].” (p.22)

Assim, a educação é libertadora quando contribui para a formação de mentes questionadoras e investigadoras. Ela tem potencial, tanto para formar revolucionárias (os), quanto para formar trabalhadores (as) explorados e alienados, constituintes do antagonismo estrutural da sociedade capitalista. Cabe aos educadores pensarem que ser humano desejam formar, para que compreendam que, para o desenvolvimento das lutas pelos direitos sociais, precisamos educar crianças feministas.

Paulo Freire (1998) destaca que:

Não existe tal coisa como um processo de educação neutra. Educação ou funciona como um instrumento que é usado para facilitar a integração das gerações na lógica do atual sistema e trazer conformidade com ele, ou ela se torna a "prática da liberdade", o meio pelo qual homens e mulheres lidam de forma crítica com a realidade e descobrem como participar na transformação do seu mundo. (p. 30).

Portanto, para que possamos modificar a realidade das mulheres no mundo, precisamos pensar uma educação que as liberte das amarras que perpetuam a manutenção das relações de poder, ou seja, para que a escola forme cidadãos, homens e mulheres, feministas o rompimento com as relações hierárquicas presentes nas salas de aula tradicionais é fundamental.

Essas relações estão presentes em todas as áreas de conhecimento do Ensino: nas ciências naturais, sociais, humanas, exatas, etc. Mariano et al. (2021) reafirma o exposto ao analisar as lutas no combate ao preconceito de gênero na Educação Física Escolar no artigo "destaca a existência latente do preconceito direcionado a mulheres e afirma que ele é "[...] arraigado por questões históricas, culturais, sociais e legislativas que marcaram épocas. (p.13). Já Albuquerque \& Silva (2019) afirmam que nas Ciências Naturais, as relações de poder se estabelecem por meio do gênero e restringem o acesso da mulher às Ciências, pois: 
A Ciência, por exemplo, é associada à uma prática masculina, enquanto resultado desta construção de papeis sociais determinada pela classe dominante e estimulada pela família e escola, utilizando-se do determinismo biológico para hierarquizar indivíduos e reforçar as diferenças entre homens e mulheres. (p. 10)

Entretanto, para educar crianças feministas, conforme Ngozi Adichie (2017), é preciso estar atento aos mínimos detalhes. Desde a linguagem utilizada até a maneira diferente que ensinamos meninas e meninos a lidarem com suas emoções. Deve-se ensinar, principalmente, que papéis de gênero são ilógicos e despropositados e que meninas nunca devem deixar de fazer algo sob a justificativa: "você é menina": jogar futebol, praticar artes marciais, sujar-se, sentar-se confortavelmente ou demonstrar emoções fortes como a raiva. Elas precisam compreender que não precisam agradar os meninos e que seus sonhos e necessidades são importantes.

Ngozi Adichie (2017) ressalta que precisamos ensinar também aos meninos que eles não só podem, como devem falar de suas emoções e que podem ser vulneráveis. Para isso, as crianças precisam ter referências de histórias, filmes, brincadeiras, livros de meninas protagonistas e de meninos que reconheçam e respeitem a alteridade feminina. Além disso, as crianças precisam ser estimuladas a adquirirem o hábito da leitura, pois é através da leitura que serão capazes de questionar o instituído.

A maneira como chamamos as meninas também pode influenciar na maneira como ela se vê no mundo. Se uma menina é chamada de "princesa", que referências dessa figura da literatura estão compondo seu imaginário? Para que esse modo de tratamento possibilite uma educação feminista, é necessário prover inúmeras referências de princesas que não simbolizem a fragilidade à espera da salvação de um homem, e sim, princesas independentes, que colocam o sentido de suas vidas na perseguição de seus sonhos e não apenas em um casamento idealizado. Ngozi Adichie (2017) ressalta que é importante ensinar as crianças que o casamento pode ser algo muito legal, mas que não é a regra da felicidade. Muitas crianças, na Educação Infantil, principalmente, sofrem muito com a separação dos pais, por terem aprendido, no contexto familiar e/ou pelos contos de fadas que o casamento é perpétuo e traz felicidade eterna.

Portanto, uma educação feminista precisa fazer parte não somente da formação inicial, mas também da formação continuada dos educadores e precisa estar presente em todos os níveis de ensino. Nessa direção, desde o Berçário, precisamos educar crianças autônomas, pesquisadoras, questionadoras e protagonistas do próprio aprendizado. Crianças não são adultos inacabados e por isso devem ser respeitadas e incentivadas em sua essência, pois possuem identidade, interesses e opiniões próprias, fatores que devem ser considerados para uma educação feminista.

Paulo Freire (1998) defende que a educação libertadora constitui-se num processo de aprendizagem mútuo onde ambos aprendem, estudante e professor. Porém, não estão as escolas ainda reproduzindo o modelo de educação que Freire denomina como "bancária", na qual o educador é o detentor do saber e o aluno o recebe passivamente? Para superar esse modelo, é substancial repensar a maneira como educa-se, reconhecendo que para ser um(a) educador(a) feminista, a desconstrução e reconstrução de saberes é essencial a cada novo desafio que se enfrenta, porque:

[...] nós, como professores - em todos os níveis do ensino fundamental à universidade - temos de reconhecer que nosso estilo de ensino tem de mudar. Vamos encarar a realidade: a maioria de nós frequentamos escolas onde o estilo de ensino refletia a noção de uma única norma de pensamento e experiência, a qual éramos encorajados a crer que fosse universal. Isso vale tanto para os professores não brancos quanto para os brancos. A maioria de nós aprendemos a ensinar imitando esse modelo. (Hooks, 2013, p.51).

Para esquivar-se desse modelo obsoleto de ensino através do qual os professores foram educados, a escola precisa ser o lugar para que as crianças descubram e compreendam o mundo em que vivem, algo que só pode ocorrer em um ambiente em que a criança se sinta participativa. A escola deve ser para o (a) aprendiz um lugar de fala política, para que aprenda cedo a expor suas ideias e a questioná-las. Para que assim, sinta-se como parte de um todo, um sujeito de direitos, capaz de questionar a 
realidade a sua volta confrontando-a e conforme hooks (2013, p.27) “[ ...] buscando não somente o conhecimento que está nos livros, mas também o conhecimento acerca de como viver no mundo."

O sociólogo Émile Durkheim (2007, p.61) ressalta que “[...] uma sociedade não pode ter outra moral senão aquela que já está contida em sua estrutura”. Logo, parte-se da premissa de que a sociedade, que rege a moral, é mutável, portanto, se o indivíduo se transforma, possíveis desdobramentos poderiam causar a mudança de grupos, e consequentemente, da sociedade como todo. Isso, porque:

[...] ela não está fora de nós por completo: também está em nós. Não está verdadeiramente viva e não é real senão nas consciências particulares. Está dentro de nós e fora de nós. É a melhor parte de nós mesmos. Tudo aquilo que existe em nós de autenticamente humano provém da sociedade, tudo aquilo que constitui a nossa consciência, enquanto homens, vem da sociedade. (Durkheim, 2007, p.12).

Sendo assim, a moral social, que rege nossos comportamentos, é a construção de uma consciência coletiva e como fruto da coletividade também é o que resulta da inter-relação das consciências individuais que a compõem. Ou seja, basta avaliarmos o sistema moral de uma sociedade para que possamos compreender o papel social assumido por diferentes agrupamentos, e como eles são vistos pelo todo. Assim, Arroyo (2003) ratifica a presença dos movimentos sociais na teoria pedagógica, pois afirma que ela "crescerá se se alimentar das virtualidades educativas presentes nos movimentos sociais pelo fato deles reporem os perenes questionamentos da condição humana."(p.20)

Nesse sentido, a responsabilidade de repassar às novas gerações o código moral instituído é da educação, que acaba por impor às crianças o código moral dominante, ou seja, o código moral do capitalismo, pois a sociedade tem na escola o papel de socializador das regras, de ensinar como se viver para ser aceito e valorizado pelo corpo social. Por isso, esse é também o espaço no qual pode-se afirmar outra moralidade possível - uma ética desde a perspectiva feminista da educação.

A função social da escola, para além do desenvolvimento das potencialidades do indivíduo, é também a de transmitir a cultura e a história da sociedade para as novas gerações, assim como, as transformações sofridas, ou impostas, ao longo do tempo nas relações humanas, econômicas e políticas.

Mas pequenas ilhas não são suficientes. É nossa relação com o trabalho intelectual e as instituições acadêmicas que têm que ser alterada. Os estudos de mulheres são reservados para aquelas que podem pagar ou estão dispostas a fazer um sacrifício, adicionando um dia letivo aos dias de trabalho em cursos de educação continuada. Contudo, todas as mulheres deveriam ter acesso gratuito à escola. Enquanto o estudo for uma mercadoria pela qual devemos pagar, ou um passo na "caça de emprego", nossa relação com o trabalho intelectual não pode ser uma experiência libertadora. (Federici, 2019b, p.124).

\section{Considerações Finais}

Neste artigo, nos propusemos a apresentar as contribuições que o estudo da ascensão capitalista apresenta para uma educação feminista. Conclui-se que é inerente e ela, não somente porque os desdobramentos do lugar designado às mulheres nesse sistema compõem as pautas adversas à equidade social — uma pauta feminista - mas porque conhecer a História da Mulher no capitalismo é um ato de conscientização política visto que a opressão de gênero é resultado da sociedade de classes, onde o sexismo, entre outros, faz parte de sua estrutura. Por isso, buscar libertação dentro de uma perspectiva capitalista é um objetivo inatingível, pois o capital necessariamente firma-se no controle dos corpos femininos e no ocultamento de seu trabalho.

Buscou-se analisar a situação das mulheres no passado e no capitalismo contemporâneo. Foram apresentados conteúdos atinentes a uma educação feminista e suas potencialidades em todos os níveis de ensino. Lamenta-se caso o título deste trabalho tenha gerado quaisquer expectativas de que ser-lhes-ia apresentado uma fórmula ou um método revolucionário de ensino que garanta formar crianças - jovens e adultos! - feministas. Infelizmente, não há uma fórmula secreta que resolva nossos problemas como um todo. Ouso afirmar que há sim uma fórmula para a educação feminista, mas, que ela é diferente para cada indivíduo. 
Por isso, a professora (or) precisa usar não apenas seu conhecimento acadêmico teórico e conceitual, mas também seu conhecimento emocional e sua sensibilidade humana para que tenha a melhor chance de ler as dificuldades e facilidades de cada estudante.

Quando um educador vê seu aprendiz, respeita suas origens, suas motivações e sonhos, ele tem a oportunidade de promover uma educação feminista, honrando o conhecimento de vida que o aluno traz e desafiando-o a buscar novos saberes, não apenas para viver melhor no mundo, mas para construir um mundo melhor para se viver. Portanto, não se sabe exatamente como promover uma educação feminista para todos a não ser pelo nosso próprio compromisso com o estudo e com a educação para a liberdade e igualdade.

Nos dias que correm, estamos vivendo um contexto pandêmico de calamidade pública em que o governo nacional reforça constantemente através de suas ações administrativas e políticas o descaso com a fome e a morte de milhares de brasileiros por COVID-19, privilegiando a economia à proteção e sobrevivência das pessoas - disponibilizando recursos insuficientes para que as pessoas fiquem em casa em segurança. O desprezo pela fome da população pobre, em sua maioria preta e feminina, se materializa negligência com a oferta e pagamento do mísero auxílio emergencial, que por vezes, é a única fonte de renda do brasileiro que está impedido de trabalhar, ou que, põe sua vida em risco trabalhando - porque o risco de contrair uma doença mortal não é tão assustador quanto chegar em casa sem o leite do filho.

Embora vivamos momentos difíceis para acreditar em avanços sociais no Brasil, não podemos negar que o alarmante contexto político constitui uma denúncia escancarada de como a grande maioria da população brasileira está longe de conhecer a sua própria realidade de opressão, pois “[...] ainda que, por exemplo, uma pessoa ao nascer tenha a sua origem e se desenvolva no seio da classe trabalhadora, pode desenvolver identidade política com a burguesia e ter suas ações voltadas para os interesses da classe burguesa. (Cisne, 2015, p.22)".

São tempos assustadores, que ficarão marcados na história e em nossas vidas, mas que podem ser lembrados como o começo de uma grande mudança e início de uma tentativa de sociedade mais honesta, justa e desenvolvida, pois, infelizmente, ainda estamos vivendo o retrocesso. Ao escrever esse texto, muitas vezes, travei batalhas mentais contra o capitalismo e inclusive sonhei com sua derrota, mas, será que o fim imediato do capitalismo acabaria então com as mazelas do mundo? Sabemos que ele nos trouxe até aqui, mas após séculos de história estudados, seria ingênuo crer que o fim de um sistema econômico romperia com toda a construção ideológica: moral, social e política de imediato sendo essa construção praticada pela humanidade através dos tempos.

É evidente que a luta anticapitalista ainda tem muito pela frente, especialmente porque grande parte da sociedade vive com a crença de que não há alternativas ao capitalismo, a aceitação da realidade do capital condiciona nosso comportamento agindo como uma barreira invisível que delimita nosso pensamento e ação. Porém, não é necessário que tenhamos uma troca de sistema econômico para que comecemos a desatar os nós das amarras às quais somos submetidos e a educação feminista é uma das maneiras de fazê-lo.

Dado o exposto, é possível entender a importância de estudar a História da perspectiva feminina de subjugação. Os resultados e reflexões apontam para a necessidade de desdobramentos futuros com relação à temática. Nosso estudo infere que é preciso ampliar dados tão significativos como estes, porque a coesão social — corrompida pelo capitalismo — que nos foi tomada, proporciona formas coletivas de tomadas de decisão pensadas pela e para a coletividade. Por isso, sugere-se pesquisas futuras que possibilitem analisar os acontecimentos históricos a partir de outras perspectivas, reconhecendo narrativas de sujeitos diversos, que são atravessados pela dominação do sistema capitalista. 
Research, Society and Development, v. 10, n. 7, e5910716234, 2021

(CC BY 4.0) | ISSN 2525-3409 | DOI: http://dx.doi.org/10.33448/rsd-v10i7.16234

\section{Referências}

Albuquerque, A. G., \& Silva, A. M. T. B. (2019). A mulher nas Ciências Naturais: uma história de enfrentamentos e conquistas. Research, Society and Development $8,1-12$.

Aruzza, C.; Bhattacharya, T.; Fraser, N. (2019). Feminismo para os 99\%: um manifesto. São Paulo: Boitempo, 2019.127.

Cisne, M. (2015). Feminismo e consciência de classe no Brasil. São Paulo: Cortez.

Durkheim, É. (Trad. Raquel Weiss). (2007). O ensino da moral na escola primária. Novos estud. - CEBRAP, 78, 59-75.

Federici, S. (Trad. Heci Regina). (2019a) Mulheres e caça às bruxas: da Idade Média aos dias atuais. São Paulo: Boitempo.

Federici, S. (Trad. Sycorax). (2017). O Calibã e a bruxa. São Paulo: Elefante.

Federici, S. (Trad. Sycorax). (2019b). O ponto zero da revolução. São Paulo: Elefante.

Fórum Brasileiro de Segurança Pública - FBSP. (2020) Anuário brasileiro de segurança pública. Edição 14. São Paulo. https://forumseguranca.org.br/anuariobrasileiro-seguranca-publica. 27/08/2020.

Freire, P. (1998) Pedagogia do Oprimido. 25a edição. Rio de Janeiro: Paz e Terra

Gohn, M. G. (2011). Movimentos sociais na contemporaneidade. Revista Brasileira de Educação, 333-361.

Hooks, b. (2017) Ensinando a transgredir: a educação como prática da liberdade. São Paulo: WMF Martins Fontes.

Lessa, S. (2014) O revolucionário e o estudo: Por que não estudamos? São Paulo: Instituto Lukács.

Machado, R. N. S. (2012). Relações de gênero na prática pedagógica. XVI Encontro Nacional de Didática e Práticas de Ensino, 14-25.

Mariano, E. R., Silva, F. E. L., Souza, S., Rizzo, D., Rosa, V. A. V., \& Monteiro, L. F. (2021). Elas podem se machucar: As Lutas no combate ao preconceito de gênero na Educação Física Escolar. Research, Development and Society,1-16. https://doi.org/http://dx.doi.org/10.33448/rsd-v10i3.12946

Ngozi, C. A. (2017) Para educar crianças feministas: um manifesto. São Paulo: Companhia das Letras.

Saffioti, H. (2015) Gênero, patriarcado e violência. São Paulo: Expressão Popular.

Santos, F. K. L., Pessoa, B. G. F., Silva, R. G., Silva, L. D., Araújo, N. J. C., Monte, L. M. I., \& Nascimento, E. F. (2020). Cultura do estupro: o machismo manifesto nas paradas musicais. Research, Society and Development, https://doi.org/http://dx.doi.org/10.33448/rsd-v9i7.4097

Silva, A. F. C., Alves, C. G., Machado, G. D., Meine, I. R., Silva, R. M., \& Carlesso, J. P. P. (2020). Violência doméstica contra a mulher: contexto sociocultural e saúde mental da vítima. Research, development and society, 9. https://doi.org/http://dx.doi.org/10.33448/rsd-v9i3.2363

Sousa, I. N., Santos, F. C., \& Antonietti, C. C. (2021). Fatores desencadeantes da violência contra a mulher na pandemia COVID-19: Revisão integrativa. Revisa. https://doi.org/10.36239/revisa. 51-60.

Wolf, N. (1992) O Mito da Beleza: como as Imagens de Beleza são usadas contra as Mulheres. (Trad. W. Barcellos). Rio de Janeiro: Rocco. 